\title{
PEMERIKSAAN SENSIBILITAS DAN STIMULASI SOMATOSENSORIK PADA KAKI LANSIA DI UPTS TRESNA WREDHA PANDAAN JAWA TIMUR
}

\section{EXAMINATION OF SENSIBILITY AND FOOT'S SOMATOSENSORY STIMULATION IN ELDERLY AT TRESNA WREDHA NURSING HOME PANDAAN EAST JAVA}

\author{
${ }^{1}$ Khabib abdullah, ${ }^{2}$ Atik swandari, ${ }^{3}$ Jihan Tsabita, ${ }^{4}$ Mutiara firdaus \\ 1,2 Prodi S1 Fisioterapi Universitas Muhammadiyah Surabaya, Jl. Suterojo 59 Surabaya Jawa \\ Timur. \\ ${ }^{3,4}$ Mahasiswa Prodi S1 Fisioterapi Universitas Muhammadiyah Surabaya, Jl. Suterojo 59 \\ Surabaya Jawa Timur. \\ Email : abi337587@gmail.com
}

\begin{abstract}
ABSTRAK
Lansia memiliki risiko jatuh yang cukup besar. Menurut WHO, bahwa lansia usia 65 tahun ke atas memiliki risiko jatuh sebesar 28-35\%. Lansia yang tinggal di panti jompo memiliki risiko jatuh yang lebih besar dibandingkan dengan lansia yang tinggal di rumah pribadi. Salah satu penyebab lansia mudah terjatuh adalah penurunan fungsi keseimbangan. Secara konsep, keseimbangan gerak terdiri dari komponen-komponen penglihatan, fungsi vestibular, fungsi muskuloskeletal dan sensibilitas telapak kaki. Kemampuan sensibilitas telapak kaki merupakan kemampuan lansia dalam merasakan sentuhan/taktil pada kaki dan kemampuan merasakan gerakan/proprioseptif pada kaki. Fungsi taktil dan proprioseptif pada kaki inilah yang menjadi pondasi kemampuan berjalan tanpa terjatuh atau kehilangan keseimbangan. Jika komponen sensibilitas telapak kaki tadi mengalami penurunan, maka lansia akan berpotensi mengalami gangguan keseimbangan saat berjalan. Sehingga tujuan dilakukan kegiatan ini adalah untuk memeriksa sensibilitas telapak kaki lansia penghuni panti dan untuk memberikan stimulasi rangsangan pada reseptor taktil dan proprioseptor diatas. Kegiatan ini dilaksanakan pada Sabtu 29 Mei 2021 secara luring dengan sasaran PkM adalah lansia di Panti Tresna Wredha Pandaan. Teknik yang digunakan adalah pemeriksaan dan intervensi fisioterapi secara langsung dengan hasil 22 lansia mengalami gangguan sensibilitas ringan, 3 lansia mengalami gangguan sensibilitas sedang dan 15 mengalami gangguan sensibilitas berat. Setelah diberikan stimulasi, sebagian besar lansia merasakan nyaman dan ringan saat berjalan, dan bahagia karena merasa diperhatikan. Untuk saran kegiatan ini adalah mengajarkan stimulasi pada pengelola panti dan perawat panti, serta lansia di panti, untuk menghafal gerakan stimulasi supaya manfaat stimulasi lebih optimal.
\end{abstract}

Kata Kunci : sensibilitas, telapak kaki, stimulasi somatosensorik, lansia, keseimbangan

\section{ABSTRACT}

The elderly have a considerable risk of falling. According to $W H O$, elderly people aged 65 years and over have a 28-35\% risk of falling. The elderly who live in nursing homes have a greater risk of falling than the elderly who live in private homes. One of the causes for the elderly to fall easily is a decrease in balance function. Conceptually, the balance of motion consists of components of vision, vestibular function, musculoskeletal function and foot sensibility. Foot sensibility is the ability of the elderly to feel touch/tactile on the feet and the ability to feel movement/proprioceptive on the feet. The tactile and proprioceptive functions of the feet are the foundation for the ability to walk without falling or losing balance. If the sensibility component of the sole of the foot has decreased, the elderly will have the potential to experience balance disorders when walking. So the purpose of this activity is to do assesment the sensibility of the feet of the elderly in nursing homes and to provide stimulation to the tactile and proprioceptor of feet. This activity was carried out on Saturday 29 May 2021 offline with the target of PkM being the elderly at the Tresna Wredha Pandaan Home. The technique used is direct physiotherapy examination and intervention with the results that 22 of the elderly have mild sensibility disorders, 3 of the elderly have moderate sensibility disorders and 15 have severe sensibility disorders. After being given stimulation, most of the elderly feel comfortable and light when walking, and are happy because they feel cared for. The suggestion for this activity is to teach stimulation to nursing home managers and nursing home nurses, as well as the elderly in nursing homes, to memorize stimulation movements so that the benefits of stimulation are more optimal.

Keywords : sensibility, soles of the feet, somatosensory stimulation, elderly, balance 


\section{PENDAHULUAN}

Salah satu reseptor sensoris yang berperan pada keseimbangan adalah reseptor somatosensorik pada kaki. Saat berdiri dan berjalan, otak memerlukan input tekanan yang terus-menerus dari telapak kaki untuk mempertahankan keseimbangan. Selain itu, input tentang posisi persendian kaki/proprioseptif juga berperan dalam menjaga keseimbangan saat berjalan (Vaillant et al., 2009).

Kemampuan untuk mengontrol keseimbangan akan menurun seiring pertambahan usia. Proses fisiologi penurunan keseimbangan akan dimulai pada usia 45 tahun, yang salah satunya ditandai dengan penurunan sensibilitas kaki (rasa sentuh dan rasa gerak). Dengan adanya hal tersebut maka ketika berjalan, otak mengalami penurunan informasi dari telapak kaki. Ketika usia semakin bertambah, maka risiko untuk terjadi gangguan keseimbangan berjalan akan semakin besar (Mesquita et al., 2015).

Salah satu cara untuk mengatasi permasalahan di atas adalah dengan melakukan pemeriksaan sensibilitas telapak kaki dan rasa gerak pada kaki, untuk kemudian diberikan latihan stimulasi untuk mencegah gangguan keseimbangan. Kelompok usia yang tepat diberikan tindakan di atas adalah lansia, sehingga kegiatan pengabdian masyarakat ini perlu dilakukan. Lansia yang tinggal di panti wredha, perlu mendapatkan perhatian yang lebih, termasuk dalam kemampuan di atas. Pemeriksaan sensibilitas pada kaki dan stimulasinya, merupakan hal baru dalam meningkatkan kemampuan keseimbangan dan mencegah risiko jatuh pada lansia. Belum banyak kegiatan seperti ini dilakukan, padahal secara bukti penelitian sudah banyak bermanfaat (Kafa, 2015).

Dari latar belakang di atas, kami tim dosen prodi S1 Fisioterapi Universitas Muhammadiyah Surabaya beserta mahasiswa, melakukan kegiatan pemeriksaan sensibilitas dan stimulasi somatosensorik pada kaki lansia di UPTS Tresna Wredha Pandaan Jawa Timur pada Mei 2021 dengan tujuan untuk mencegah risiko jatuh pada lansia dengan memperkuat kemampuan sensibilitas kaki.

\section{METODE}

Kegiatan pengabdian masyarakat ini dilaksanakan di UPTS Tresna Wredha Pandaan dengna topik kegiatan pemeriksaan sensibilitas kaki dan stimulasi somatosensorik pada lansia ditempat tersebut. Kegiatan ini dilaksanakan pada hari sabtu 29 Mei 2021 yang bertepatan dengan peringatan HLUN (hari lanjut usia nasional). Kegiatan ini dilakukan oleh tim dosen dan mahasiswa prodi S1 Fisioterapi Universitas Muhammadiyah Surabaya. Kegiatan ini bertujuan untuk mengetahui tingkat sensibilitas telapak kaki terhadap sentuhan dan rasa gerak, kemudian dilakukan edukasi latihan somatosensorik pada kaki lansia. Metode kegiatan ini adalah sebagai berikut :

a. Lansia penghuni panti yang dapat berjalan mandiri berkumpul di aula panti

b. Penjelasan tentang kegiatan, perkenalan tim dosen dan mahasiswa

c. Pemeriksaan sensibilitas telapak kaki oleh tim dosen dan mahasiswa

d. Didapatkan angka jumlah lansia yang mengalami penurunan sensibilitas kaki

e. Melakukan edukasi stimulasi somatosensorik pada kaki lansia

f. Review gerakan stimulasi dan tanya jawab

g. Memberi saran untuk kelompok lansia yang mengalami penurunan sensibilitas kaki untuk melakukan latihan secara rutin

h. Memberi saran bagi yang tidak mengalami penurunan sensibilitas kaki, tetap ikut latihan untuk pencegahan

\section{HASIL DAN PEMBAHASAN HASIL}

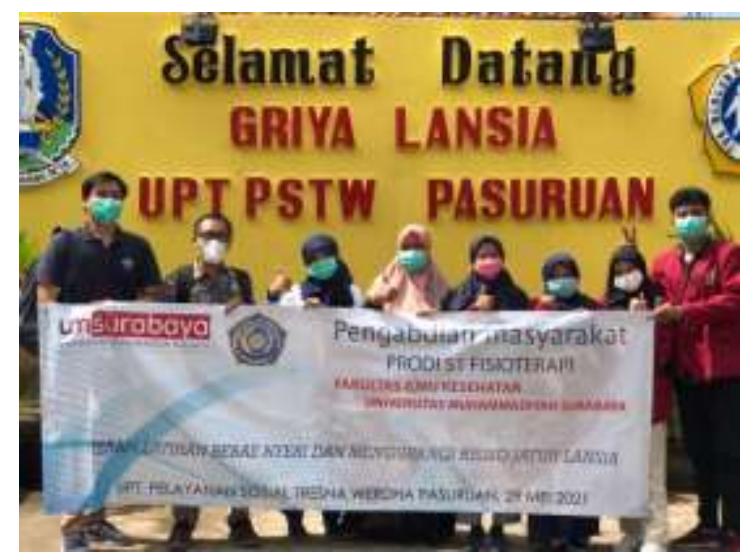



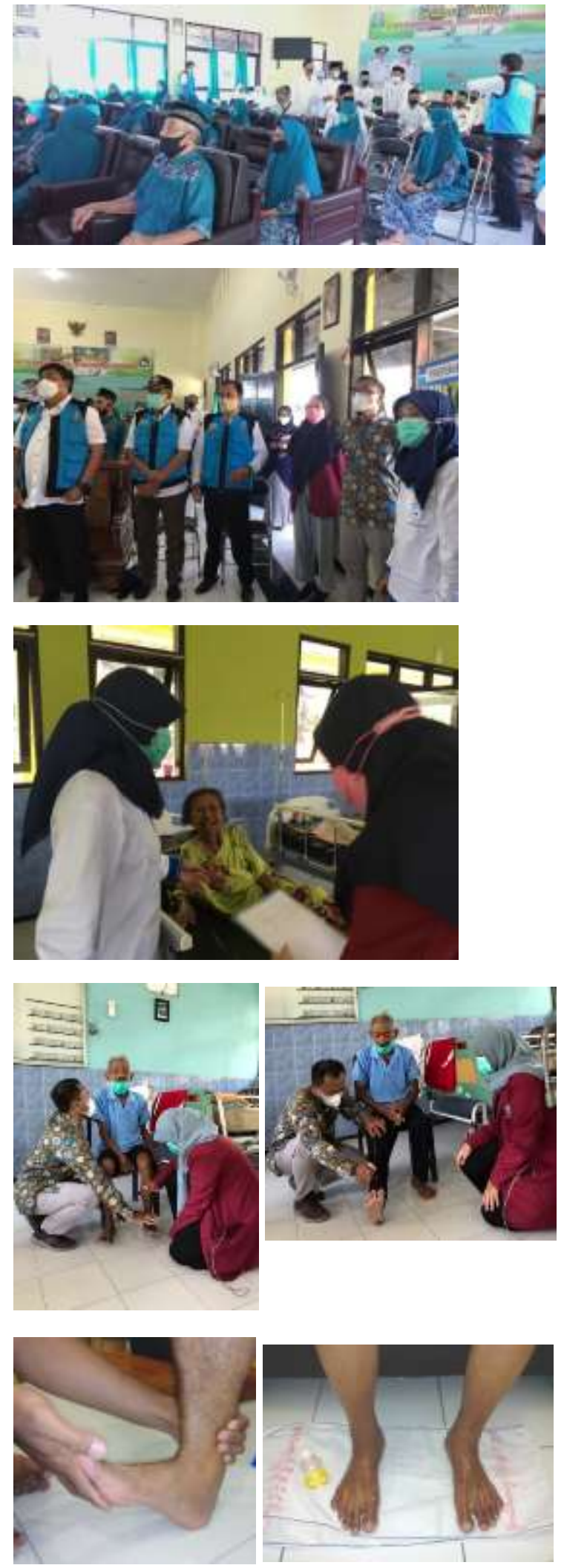

Tabel 1 Distribusi peserta berdasarkan jenis kelamin

\begin{tabular}{cccc}
\hline No & Jenis kelamin & F & Prosentase \\
\hline 1. & Laki-laki & 13 & $32 \%$ \\
2. & Perempuan & 27 & $68 \%$ \\
\hline & Total & 40 & $100 \%$ \\
\hline
\end{tabular}

Sumber : Data primer

Tabel 2 Distribusi peserta berdasarkan usia

\begin{tabular}{cccc}
\hline No & Usia & F & Prosentase \\
\hline 1. & $46-55$ tahun & 3 & $8 \%$ \\
2. & $56-65$ tahun & 14 & $35 \%$ \\
3 & $>65$ tahun & 23 & $57 \%$ \\
\hline \multicolumn{2}{c}{ Total } & 40 & $100 \%$ \\
\hline
\end{tabular}

Sumber : Data primer

Tabel 3 Distribusi peserta yang mengalami gangguan sensibilitas kaki

\begin{tabular}{cccc}
\hline No & Kategori & F & Prosentase \\
\hline 1. & Ringan & 22 & $55 \%$ \\
2. & Sedang & 3 & $7.5 \%$ \\
3 & Berat & 15 & $37.5 \%$ \\
\hline & Total & 40 & $100 \%$
\end{tabular}

Sumber : Data primer

\section{PEMBAHASAN}

Sasaran kegiatan pengabdian masyarakat ini adalah lansia di UPTS Tresna Wredha Pandaan yang dapat berjalan mandiri dan dapat berkomunikasi aktif dua arah. Dari 110 lansia penghuni panti, hanya 40 lansia yang mengikuti kegiatan ini karena syarat berjalan mandiri dan komunikasi aktif. Dari 40 lansia tersebut dilakukan pemeriksaan sensibilitas pada kedua telapak kaki dan didapatkan hasil $55 \%$ lansia mengalami gangguan sensibilitas ringan, $7,5 \%$ lansia mengalami gangguan sensibilitas sedang dan $37.5 \%$ mengalami gangguan sensibilitas berat.

Pemeriksaan gangguan sensibilitas dilakukan dengan cara memegang bagian kaki lansia, lansia tidak diperkenankan melihat, kemudian lansia menebak sisi mana dari kakinya yang dipegang/disentuh dan digerakkan. Jika lansia berhasil menjawab dengan benar hanya $75 \%$ dari pertanyaan, maka kategori penurunan sensibilitas ringan, jika 50\% dari pertanyaan maka termasuk kategori penurunan sensibilitas sedang, dan 
jika hanya benar 25\% maka termasuk gangguan sensibilitas berat.

Setelah didapatkan data tersebut, maka dilakukan edukasi berupa latihan stimulasi somatosensorik pada kaki lansia dengan rincian : gerakan menggeser handuk yang ditempatkan di kaki lansia, kemudian gerakan pada jari-jari kaki, lalu dilanjutkan dengan gerakan pada pergelangan kaki. Tiga gerakan tersebut diulang-ulang selama 10 menit.

Setelah selesai, lansia diminta berjalan sepanjang 5 meter bolak balik untuk menanamkan pola gerakan yang baru. Kemudian pada akhir sesi, lansia diberikan pertanyaan untuk mengulang tata urutan stimulasi sampai hafal/paham.

Lansia tampak senang dan antusias, beberapa bahagia dan merasa jalannya lebih ringan dari biasanya. Untuk menindaklanjuti kegiatan ini, maka kami berinisiatif untuk berkunjung secara rutin minimal sebulan sekali untuk memberikan latihan tambahan dan mengecek apakah gerakan latihan masih dilakukan dan diingat dengan baik oleh lansia di panti tersebut. Selain itu kami akan membuat buku panduan atau video latihan yang dapat dititipkan pada perawat atau pengelola panti agar latihan ini dapat dilakukan setiap hari.

\section{KESIMPULAN}

Hasil kegiatan pengabdian masyarakat pemeriksaan sensibilitas dan stimulasi somatosensorik pada kaki lansia di UPTS tresna wredha pandaan jawa timur yaitu didapatkan sebanyak 15 lansia mengalami penurunan sensibilitas kaki level berat, 3 orang level sedang, dan 22 orang level ringan, sehingga stimulasi somatosensorik pada kaki harus diajarkan secara optimal untuk mengurangi risiko jatuh dan meningkatkan keseimbangan saat berjalan.
Lansia tampak antusias dan senang dengan kegiatan ini, beberapa merasakan saat berjalan lebih ringan dari biasanya. Saran untuk kegiatan ini adalah mengajarkan pemeriksaan dan latihan untuk pengurus panti dan perawat panti, serta untuk lansia sendiri, supaya stimulasi lebih optimal. Untuk PkM selanjutnya dapat ditambahkan gerakan-gerakan lain maupun pembuatan video dan poster gerakan untuk dokumentasi yang dapat dilihat diluar kegiatan PkM.

\section{DAFTAR PUSTAKA}

Kafa, Nihan (2015), Foot Sensation, Balance and Proprioception, OMICS Group eBooks 731 Gull Ave, Foster City, CA 94404, USA.

Mesquita, Laiana; Carvalho, Fabiana; Freire, Lara; Neto, Osmar; Zangaro; Renato (2015), Effect of two exercise protocols on postural balance of eldery women : a randomized controlled trial, Biomed Central Geriatrics Journal.

Vaillant, Jacques; Rouland, Audrey; Martigne, Pascale; Braujou, Renaud; Nissen, Michael; Miousse, Jean; Vuillerme, Nicolas; Nougier, Vincent; Juvin, Robert (2009), Massage and mobilization of the feet and ankles in eldery adults : Effect on clinical balance performance, Manual Therapy Journal Elsevier.

World Health Organization (2007) ; WHO global report on falls prevention in older age 